(1)

CrossMark

\title{
Which definition of a central tumour is more predictive of occult mediastinal metastasis in nonsmall cell lung cancer patients with radiological NO disease?
}

\author{
Sun Hye Shin ${ }^{1,4}$, Dong Young Jeong ${ }^{2,4}$, Kyung Soo Lee $\mathbb{1}^{2}$, Jong Ho Cho ${ }^{3}$, \\ Yong Soo $\mathrm{Choi}^{3}$, Kyungjong Lee ${ }^{1}$, Sang-Won Um (i) ${ }^{1}$, Hojoong Kim ${ }^{1}$ and \\ Byeong-Ho Jeong ${ }^{1}$
}

Affiliations: ${ }^{1}$ Division of Pulmonary and Critical Care Medicine, Dept of Medicine, Samsung Medical Center, Sungkyunkwan University School of Medicine, Seoul, Republic of Korea. ${ }^{2}$ Dept of Radiology, Samsung Medical Center, Sungkyunkwan University School of Medicine, Seoul, Republic of Korea. ${ }^{3}$ Dept of Thoracic Surgery, Samsung Medical Center, Sungkyunkwan University School of Medicine, Seoul, Republic of Korea. ${ }^{4} T h e s e$ two authors contributed equally to this work.

Correspondence: Byeong-Ho Jeong, Division of Pulmonary and Critical Care Medicine, Dept of Medicine, Samsung Medical Center, Sungkyunkwan University School of Medicine, Irwon-ro 81, Gangnam-gu, Seoul 06351, Republic of Korea. E-mail: myacousticlungdgmail.com

@ERSpublications

Central tumours defined as located in the inner one-third of the hemithorax adopted by drawing concentric lines from the midline are associated with occult mediastinal metastasis in patients with NSCLC and radiological No disease http://ow.ly/scg630nbRmY

Cite this article as: Shin SH, Jeong DY, Lee KS, et al. Which definition of a central tumour is more predictive of occult mediastinal metastasis in nonsmall cell lung cancer patients with radiological N0 disease? Eur Respir J 2019; 53: 1801508 [https://doi.org/10.1183/13993003.01508-2018].

\section{ABSTRACT}

Background: Guidelines recommend invasive mediastinal staging for centrally located tumours, even in radiological N0 nonsmall cell lung cancer (NSCLC). However, there is no uniform definition of a central tumour that is more predictive of occult mediastinal metastasis.

Methods: A total of 1337 consecutive patients with radiological N0 disease underwent invasive mediastinal staging. Tumours were categorised into central and peripheral by seven different definitions.

Results: About 7\% (93 out of 1337) of patients had occult N2 disease, and they had significantly larger tumour size and more solid tumours on computed tomography. After adjustment for patient- and tumour-related characteristics, only the central tumour definition of the inner one-third of the hemithorax adopted by drawing concentric lines arising from the midline significantly predicted occult N2 disease (adjusted OR 2.13, 95\% CI 1.17-3.87; $\mathrm{p}=0.013$ ). This association was maintained after excluding patients with pure ground-glass nodules (adjusted OR 2.54, 95\% CI 1.37-4.71; $\mathrm{p}=0.003$ ) or only including those with solid tumours (adjusted OR 2.30, 95\% CI 1.08-4.88; $\mathrm{p}=0.030$ ).

Conclusions: We suggest that a central tumour should be defined using the inner one-third of the hemithorax adopted by drawing concentric lines from the midline. This is particularly useful for predicting occult N2 disease in patients with NSCLC.

This article has supplementary material available from erj.ersjournals.com

Received: Aug 082018 | Accepted after revision: Dec 182018

Copyright $\odot$ ERS 2019. This article is open access and distributed under the terms of the Creative Commons Attribution Non-Commercial Licence 4.0. 


\section{Introduction}

Accurate mediastinal staging is an essential step in the management of patients with nonsmall cell lung cancer (NSCLC) without distant metastases [1]. Noninvasive imaging studies including computed tomography (CT) and integrated positron emission tomography (PET)-CT are initially performed to evaluate mediastinal lymph node stage. This is followed by pathological confirmation for positive or inconclusive findings using endobronchial ultrasound-guided transbronchial needle aspiration (EBUS-TBNA) in most cases [1]. In the absence of mediastinal metastasis on CT or PET-CT images, invasive mediastinal staging is recommended only when there are one or more risk factors for occult mediastinal metastasis, such as N1 lymph node enlargement, tumour size $>3 \mathrm{~cm}$ or central location [1-3].

However, there is no uniform definition of the "central location" of tumours, even among major practice guidelines. The American College of Chest Physicians guidelines define tumours in the inner one-third of the hemithorax as centrally located [2], while the National Comprehensive Cancer Network (NCCN) and the European Society of Thoracic Surgery (ESTS) guidelines define those in the inner two-thirds of the hemithorax as centrally located $[1,3]$. This is at least partially responsible for the inconsistent findings in many studies that investigated the association between tumour location and risk of occult N2 disease using different definitions for centrally located tumours [4-13]. Likewise, a recent survey disclosed the lack of agreement among physicians regarding the definition of a "central tumour" [14]. Nevertheless, there are no studies comparing different definitions of central tumours, particularly when applying the definition in terms to predict occult N2 disease in patients with radiological N0 disease.

Thus, this study aimed to evaluate the risk of occult N2 disease in patients with NSCLC and radiological N0 disease using seven different definitions for centrally located tumours.

\section{Methods}

Study population and data collection

Using the Lung Cancer Surgery Registry and EBUS-TBNA Registry database at Samsung Medical Center (a 1979-bed referral hospital in Seoul, South Korea), patients with NSCLC and radiological N0 disease by both CT and PET-CT were retrospectively identified from the registries between January 2014 and December 2015. Radiological N0 stage was defined as short axis of lymph nodes $\leqslant 1 \mathrm{~cm}$ on CT and maximum standardised uptake value of lymph nodes $\leqslant 2.5$ on PET-CT [15]. Patients with a previous history of lung cancer, a previous history of mediastinal lymph node dissection (MLND) due to oesophageal cancer, who underwent neoadjuvant treatment, who did not undergo standard MLND (i.e. mediastinal sampling or lung resection only) or with double primary lung cancer with different histology were excluded.

Information regarding patient-related characteristics (age, sex and smoking) and tumour-related characteristics (size, lobar location and histology) were collected from the database. The primary outcome of this study was occult mediastinal lymph node metastasis (occult N2 disease), which was defined as pathologically proven (either by MLND or by EBUS-TBNA) N2 or N3 disease based on the International Association for the Study of Lung Cancer lymph node map [16]. The Institutional Review Board of Samsung Medical Center approved this study (2017-12-088-002) and waived informed consent due to its retrospective nature.

\section{Definitions for central tumour location}

Tumour locations were measured based on the inner-most part of the tumour on CT. Based on a previous study [14], tumours were categorised as central and peripheral by contact with hilar structures (i.e. lobar bronchi, lobar or main pulmonary arteries, main pulmonary veins) or by location within one-third or two-thirds of the hemithorax. Lines dividing thirds of the hemithorax were drawn as follows: concentric lines arising from the hilum in both axial and coronal images, concentric lines arising from the midline in axial images, and sagittal lines arising from the midline in coronal images (figures 1 and 2).

\section{Invasive mediastinal staging}

Patients with radiological N0 disease without distant metastasis either underwent pre-operative EBUS-TBNA or directly proceeded to surgical resection at the discretion of attending physicians, since there was no consistent indication for pre-operative EBUS-TBNA in patients with radiological N0 disease. EBUS-TBNA was performed with a convex probe EBUS bronchoscope (BF-UC260F-OL8; Olympus, Tokyo, Japan) and a 22-gauge needle (NA-201SX-4022; Olympus) under moderate sedation with intravenous midazolam and fentanyl. After systematic inspection of lymph node stations, each visible lymph node was sampled in the standard N3 to N2 to N1 fashion, with size cut-offs of $\geqslant 5 \mathrm{~mm}$ in the short axis by EBUS. We conducted three passes per node and at least two passes when core tissue was obtained [17, 18]. Transoesophageal bronchoscopic ultrasound-guided fine-needle aspiration 


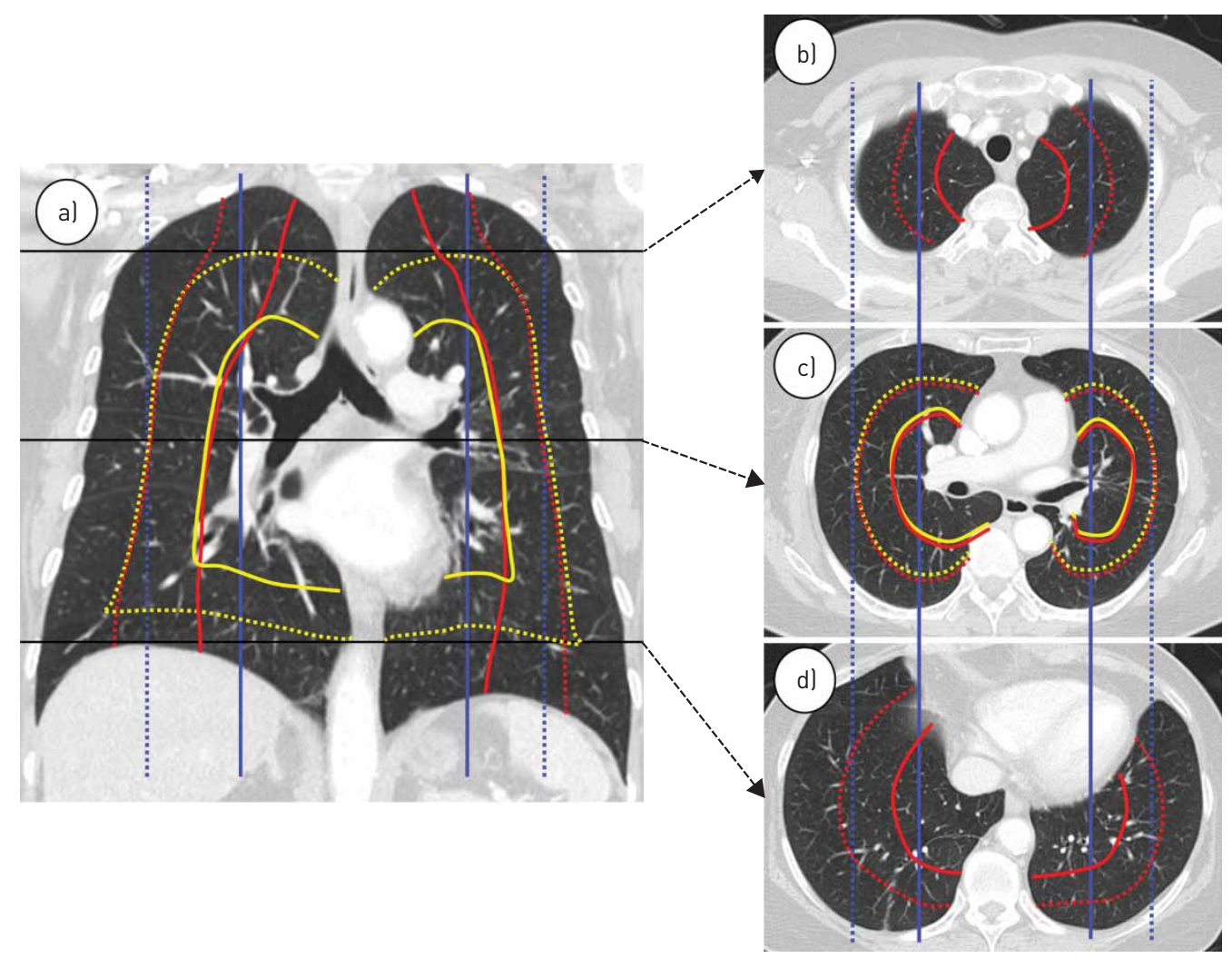

FIGURE 1 Definitions of lines that determine tumour location. CT: computed tomography. Concentric lines arising from the hilum (yellow lines) are spherical or dumbbell shaped in three dimensions. Concentric lines arising from the midline (red lines) are cylindrical or conical in three dimensions. Sagittal lines arising from the midline (blue lines) are rectangular parallelepipeds in three dimensions. Solid lines and broken lines refer to the inner one-third and two-thirds lines, respectively. a) Coronal CT at the tracheal bifurcation level. b) Axial CT image at the manubrium body level. There is no yellow line because it arises from the hilum. c) Axial CT image at the hilum level. The red and yellow lines are the same. d) Axial CT image at just above the diaphragm. There is no yellow line because it arises from the hilum.

(EUS-FNA-B) using the EBUS bronchoscope was done in selected cases [19]. Rapid on-site cytopathological evaluation was not available. When the clinical suspicion of mediastinal metastasis remained high despite a negative result in EBUS-TBNA, pre-operative mediastinoscopy was performed. Otherwise, surgical resection with MLND was considered if there was no metastasis to mediastinal lymph nodes in EBUS-TBNA.

a)

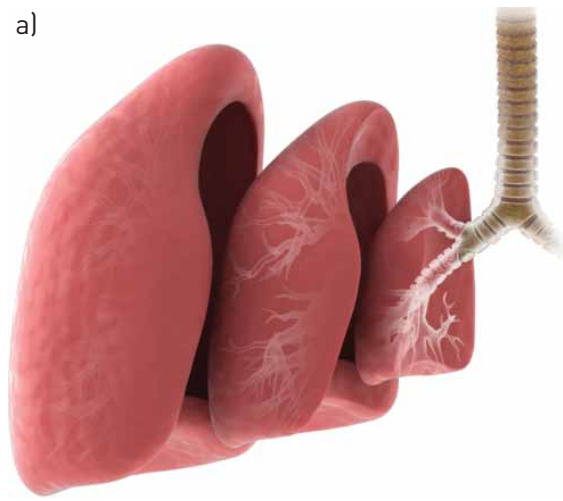

b)

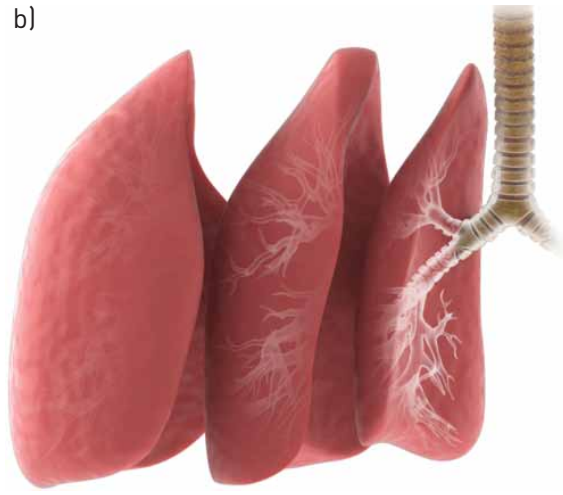

c)

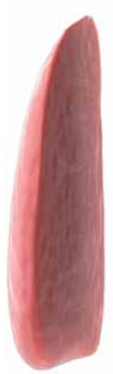

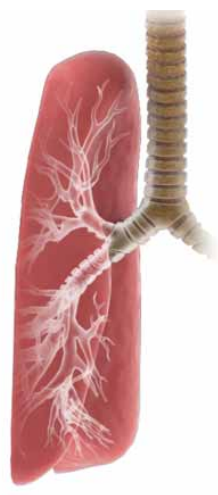

FIGURE 2 Conceptual three-dimensional images of a) concentric lines arising from the hilum (corresponding to the yellow lines in figure 1), b) concentric lines arising from the midline (corresponding to the red lines in figure 1) and c) sagittal lines arising from the midline (corresponding to the blue lines in figure 1). 
The surgical procedures included resection of the affected lung plus lymph node dissection of the ipsilateral hilum and mediastinum, including all visible and palpable lymph nodes irrespective of size [20, 21]. MLND consisted of en bloc resections of all nodes at stations $10 \mathrm{R}, 9,8,7,4 \mathrm{R}, 3$ and $2 \mathrm{R}$ for right-sided tumours and nodes at stations $10 \mathrm{~L}, 9,8,7,6,5$ and $4 \mathrm{~L}$ for left-sided tumours.

\section{Statistical analyses}

Data are reported as number (percentage) for categorical variables and as mean with standard deviation for continuous variables. Data were compared using the Chi-squared test or Fisher's exact test for categorical variables, and the t-test for continuous variables. Multivariable logistic regression analysis was used to adjust for potential confounding factors in the association between seven central tumour definitions and occult N2 disease. Two models were constructed: Model 1 was adjusted for tumour size (continuous) and tumour attenuation on CT; Model 2 was additionally adjusted for age (continuous), sex, smoking history (never-smoker or ever-smoker) and lobar location (right or left) of tumour. Analyses were also performed in subgroups of patients excluding pure ground-glass lesions $(n=861)$ and in those with solid tumours only $(\mathrm{n}=485)$. All tests were two-sided and a $\mathrm{p}$-value $<0.05$ was considered significant. Stata version 14.0 (StataCorp, College Station, TX, USA) was used for analysis.

\section{Results}

\section{Study population}

During the study period, 159 patients in the EBUS-TBNA Registry were suspected to have radiological N0 NSCLC and underwent EBUS-TBNA for nodal staging (figure 3). Of these patients, 10 were confirmed to have N2 disease. The remaining 149 patients underwent curative resection. In the Lung Cancer Surgery Registry, 1526 patients underwent curative resection for radiological N0 NSCLC. After 199 patients were excluded (mediastinal sampling only $(n=135)$, previous history of lung cancer $(n=29)$, lung resection without MLND ( $n=12)$, lung resection after neoadjuvant treatment $(n=11)$, previous history of MLND due to oesophageal cancer $(n=7)$ and double primary lung cancer $(n=5)), 83$ patients were confirmed to have N2 disease by MLND. Finally, $93(7.0 \%)$ patients were confirmed to have occult N2 disease by EBUS-TBNA or MLND in 1337 patients with radiological N0 disease. Of these 93 patients with occult N2 disease, two also had metastases to N3 lymph nodes. Meanwhile, there were 27 patients who received pre-operative mediastinoscopy and none of them was found to have occult N2 disease.

\section{Patient and tumour characteristics}

Characteristics of the 1337 patients are shown in table 1 . The mean age of patients was 62 years, $53 \%$ of patients were male and $52 \%$ of patients were never-smokers. Tumour size was $\leqslant 3 \mathrm{~cm}$ in $63 \%$ of cases. CT attenuation was solid in $36 \%$ of cases and most tumours (82\%) were adenocarcinoma on histology. Baseline characteristics including age, sex, smoking history, tumour location and tumour histology were not associated with the risk of occult N2 disease in univariate analysis. However, larger tumour size $(\mathrm{p}<0.001)$ and increasing tumour attenuation on CT $(\mathrm{p}=0.001)$ were significantly associated with increased risk of occult N2 disease. Time interval between PET-CT and surgery, and the number of dissected nodes or dissected lymph node stations, were not associated with the increased risk of occult N2 disease.

Exclusions ( $n=199)$ :

Mediastinal sampling only $(n=135)$

Previous history of lung cancer $(n=29)$

Lung resection without MLND ( $\mathrm{n}=12)$

Neoadjuvant treatment $(n=11)$

Double primary lung cancer with different

histology ( $n=5)$
Previous history of MLND $(n=7)$

Lung Cancer Surgery Registry

Curative resection for NSCLC between January 2014 and December 2015 ( $n=2235)$

FIGURE 3 CONSORT diagram of the study population. EBUS-TBNA: endobronchial ultrasound-guided transbronchial needle aspiration; NSCLC: nonsmall cell lung cancer; MLND: mediastinal lymph node dissection; pN: pathological nodal stage.
EBUS-TBNA Registry

Staging EBUS-TBNA for NSCLC between January 2014 and December 2015 ( $n=980$ )




TABLE 1 Clinical characteristics by pathological nodal stage in patients with radiological NO nonsmall cell lung cancer (NSCLC)

\begin{tabular}{|c|c|c|c|c|c|}
\hline & Overall & $\begin{array}{l}\text { Pathological } \\
\text { N0 or N1 }\end{array}$ & $\begin{array}{l}\text { Pathological } \\
\text { N2 or N3 }\end{array}$ & $p$-value $e^{\pi}$ & $\begin{array}{l}\text { Univariate OR } \\
\text { (95\% CI] }\end{array}$ \\
\hline Subjects & 1337 & 1244 & 93 & & \\
\hline Age years & $61.9 \pm 9.5$ & $61.9 \pm 9.5$ & $61.0 \pm 10.3$ & $0.366^{+}$ & $0.99(0.97-1.01)$ \\
\hline Sex & & & & 0.824 & \\
\hline Female & 633 (47.3) & $590(47.4)$ & $43(46.2)$ & & 1.00 (reference) \\
\hline Male & 704 (52.7) & $654(52.6)$ & 50 (53.8) & & $1.05(0.69-1.60)$ \\
\hline Smoking status & & & & 0.310 & \\
\hline Never-smoker & $693(51.8)$ & 645 (51.9) & $48(51.6)$ & & 1.00 (reference) \\
\hline Ex-smoker & 438 (32.8) & $412(33.1)$ & $26(28.0)$ & & $0.85(0.52-1.39)$ \\
\hline Current smoker & $206(15.4)$ & $187(15.0)$ & $19(20.4)$ & & $1.36(0.78-2.38)$ \\
\hline Size of tumour $\mathrm{cm}^{f}$ & $2.85 \pm 1.59$ & $2.79 \pm 1.55$ & $3.70 \pm 1.80$ & $<0.001^{+, \# \#}$ & $1.32(1.19-1.46)$ \\
\hline$\leqslant 3$ & 838 (62.7) & 799 (64.2) & 39 (41.9) & & 1.00 (reference) \\
\hline$>3-\leqslant 5$ & $375(28.0)$ & 339 (27.3) & 36 (38.7) & & $2.18(1.36-3.48)$ \\
\hline$>5$ & $124(9.3)$ & $106(8.5)$ & $18(19.4)$ & & $3.48(1.92-6.30)$ \\
\hline Lobar location & & & & 0.176 & \\
\hline Right upper & $423(31.6)$ & 394 (31.7) & $29(31.2)$ & & 1.00 (reference) \\
\hline Right middle & $104(7.8)$ & $98(7.9)$ & $6(6.5)$ & & $0.83(0.34-2.06)$ \\
\hline Right lower & $269(20.1)$ & $246(19.8)$ & $23(24.7)$ & & $1.27(0.72-2.25)$ \\
\hline Left upper & $330(24.7)$ & 315 (25.3) & $15(16.1)$ & & $0.65(0.34-1.23)$ \\
\hline Left lower & $211(15.8)$ & $191(15.3)$ & $20(21.5)$ & & $1.42(0.78-2.58)$ \\
\hline Tumour attenuation on $\mathrm{CT}$ & & & & 0.001 & \\
\hline Ground glass & $476(35.6)$ & $451(36.3)$ & $25(26.9)$ & & 1.00 (reference) \\
\hline Part solid & $376(28.1)$ & $359(28.9)$ & 17 (18.3) & & $0.85(0.45-1.61)$ \\
\hline Solid & $485(36.3)$ & $434(34.9)$ & $51(54.8)$ & & $2.12(1.29-3.48)$ \\
\hline $\begin{array}{l}\text { Time between PET-CT and } \\
\text { surgery days }\end{array}$ & $25.2 \pm 21.2$ & $25.4 \pm 21.3$ & $22.9 \pm 20.1$ & $0.265^{+}$ & $0.99(0.98-1.01)$ \\
\hline Histology of tumour & & & & $0.097^{\S}$ & \\
\hline Adenocarcinoma & 1089 (81.5) & $1010(81.2)$ & 79 (85.0) & & 1.00 (reference) \\
\hline Squamous cell carcinoma & $199(14.9)$ & $191(15.4)$ & $8(8.6)$ & & $0.54(0.25-1.13)$ \\
\hline Large cell carcinoma & $27(2.0)$ & $24(1.9)$ & $3(3.2)$ & & $1.60(0.47-5.42)$ \\
\hline Other NSCLC & $22(1.6)$ & $19(1.5)$ & 3 (3.2) & & $2.02(0.58-6.97)$ \\
\hline \multicolumn{6}{|l|}{$\begin{array}{l}\text { Dissected nodes and } \\
\text { stations during MLND } \mathrm{n}^{++}\end{array}$} \\
\hline Lymph nodes & $15.2 \pm 8.1$ & $15.1 \pm 8.1$ & $16.5 \pm 7.9$ & $0.142^{+}$ & $1.02(0.99-1.05)$ \\
\hline Stations & $4.6 \pm 1.4$ & $4.6 \pm 1.4$ & $4.7 \pm 1.5$ & $0.460^{+}$ & $1.06(0.90-1.25)$ \\
\hline
\end{tabular}

Data are presented as $n$, mean \pm SD or $n(\%)$, unless otherwise stated. CT: computed tomography; PET: positron emission tomography; MLND: mediastinal lymph node dissection; EBUS-TBNA: endobronchial ultrasound-guided transbronchial needle aspiration. \#: two patients had occult metastasis to N3 nodes as well as N2 nodes; ": p-values are reported by the Chi-squared test except where otherwise noted $I^{+}$: two-sample t-test; ${ }^{\S}$ : Fisher's exact test) and are not the $p$-values for the odds ratio reported from univariate analysis; ${ }^{f}$ : size of the tumour is measured in pre-operative CT scan; \#\#: p-values for the two-sample t-test and Chi-squared test are <0.001; "1\%: for 10 patients who were confirmed to have N2 disease in EBUS-TBNA, the intervals between PET-CT and EBUS-TBNA were used; ${ }^{++}$: analysis was done in 1327 patients after excluding 10 patients who were confirmed to have N2 disease in EBUS-TBNA and did not undergo MLND.

Central tumour definition and the risk of occult N2 disease

The proportion of centrally located tumours varied widely from $9.1 \%$ to $80.3 \%$ using seven different definitions (table 2). By all definitions except the inner two-thirds of the hemithorax by sagittal lines, the central location was associated with increased risk of occult N2 disease in univariate analysis. However, only the central location defined as the inner one-third of the hemithorax by concentric lines arising from the midline remained statistically significant after adjustment for tumour size and attenuation on CT (adjusted OR 2.05, 95\% CI 1.14-3.71; $\mathrm{p}=0.017$ ), and with further adjustment for age, sex, smoking history and lobar location of tumour (adjusted OR 2.13, 95\% CI 1.17-3.87; $\mathrm{p}=0.013$ ).

When the analyses were confined to patients excluding pure ground-glass lesions $(n=861)$ (supplementary tables E1 and E2) or those with solid tumours only $(\mathrm{n}=485)$ (supplementary tables E3 and E4), results were grossly unchanged. The definition of the inner one-third of the hemithorax by concentric lines arising from the midline was significantly associated with increased risk of occult N2 disease in both 
TABLE 2 Risk of occult N2 disease according to each definition of a centrally located tumour in patients with radiological N0 nonsmall cell lung cancer

\begin{tabular}{|c|c|c|c|c|c|c|c|}
\hline Definition of central location & $\begin{array}{c}\text { Patients } \\
\text { n (\%) }\end{array}$ & \multicolumn{2}{|c|}{ Crude model } & \multicolumn{2}{|l|}{ Model $1 \#$} & \multicolumn{2}{|c|}{ Model $2^{\text {ๆ }}$} \\
\hline $\begin{array}{l}\text { Contact with the hilar structure } \\
\text { Concentric lines arising from } \\
\text { the hilum }\end{array}$ & $122(9.1)$ & $1.86(1.02-3.40)$ & 0.042 & $1.16(0.59-2.29)$ & 0.671 & $1.26(0.63-2.54)$ & 0.510 \\
\hline Inner one-third & $216(16.2)$ & $1.91(1.17-3.11)$ & 0.010 & $1.29(0.75-2.23)$ & 0.358 & $1.33(0.77-2.31)$ & 0.311 \\
\hline \multicolumn{8}{|l|}{$\begin{array}{l}\text { Concentric lines arising from } \\
\text { the midline }\end{array}$} \\
\hline Inner one-third & $161(12.0)$ & $2.63(1.59-4.36)$ & $<0.001$ & $2.05(1.14-3.71)$ & 0.017 & $2.13(1.17-3.87)$ & 0.013 \\
\hline Inner two-thirds & $696(52.1)$ & $2.03(1.29-3.18)$ & 0.002 & $1.50(0.92-2.46)$ & 0.104 & $1.48(0.90-2.42)$ & 0.121 \\
\hline \multicolumn{8}{|l|}{$\begin{array}{l}\text { Sagittal lines arising from the } \\
\text { midline }\end{array}$} \\
\hline Inner one-third & $358(26.8)$ & $1.81(1.17-2.80)$ & 0.008 & $1.57(0.90-2.73)$ & 0.113 & $1.59(0.91-2.79)$ & 0.101 \\
\hline
\end{tabular}

subgroups excluding pure ground-glass lesions (adjusted OR 2.54, 95\% CI 1.37-4.71; p=0.003) and subgroups with solid tumours only (adjusted OR 2.30, 95\% CI 1.08-4.88; p=0.030).

\section{Discussion}

In our study, the prevalence of pathologically proven occult N2 disease in patients with NSCLC and radiological N0 disease was 7\%. Previously recognised factors, including tumour size, tumour attenuation on CT and tumour histology, were again associated with risk of occult N2 disease [5, 8, 9, 11-13, 22]. After adjustment for these factors, only the central tumours defined as located in the inner one-third of the hemithorax adopted by drawing concentric lines from the midline were associated with increased risk of occult N2 disease, among the seven different definitions compared in this study. In the subgroup analyses excluding pure ground-glass lesions or patients with solid tumours only, the association persisted. To the best of our knowledge, our study included the largest number of patients with NSCLC exclusively with radiological N0 disease. In addition, this is the first study to compare different definitions of central tumours to predict occult N2 disease.

Previous studies mostly found that central tumours have higher risk of occult N2 disease in patients with radiological N0 NSCLC, compared with peripheral tumours. However, there are considerable inconsistencies in the definitions of centrally located tumours, especially regarding the inner one-third versus inner two-thirds in the hemithorax. Among studies which used the inner one-third as the definition of central tumours, three studies restricted their study population to those with radiological N0 disease $[7,10,13]$. Central location was independently associated with occult N2 disease in two studies (adjusted OR 6.8 and 6.25; both $\mathrm{p}<0.001)[10,13]$, while it was not associated with occult $\mathrm{N} 2$ disease in a smaller study [7]. Similarly, two studies in patients with radiological N0 disease used the inner two-thirds as the definition of central tumours $[5,9]$. One of these studies showed that central location was associated with occult N2 disease in a univariate analysis $(\mathrm{p}<0.001)$ [5] and the other study also demonstrated the increased risk of occult $\mathrm{N} 2$ disease in patients with central tumours (adjusted OR 3.2; $\mathrm{p}=0.002$ ) [9]. Of note, there was one study in which both definitions, i.e. inner one-third and inner two-thirds, were evaluated for risk of pathological N2 disease, which revealed that neither was associated with pathological N2 disease [11]. However, that study included a considerable number of patients with radiological N1, N2 or even N3 disease by CT or PET-CT, which might explain the negative results. By confining the study population to radiological N0 stage and adjusting for major confounders, our study confirmed that location in the inner one-third by concentric lines arising from the midline is the definition of a central tumour that best predicts occult $\mathrm{N} 2$ disease.

The most intriguing finding of our study is the difference between two types of concentric lines. Those arising from the hilum, which are the same as concentric lines used in an online survey [14], were less predictive of occult N2 disease compared with those arising from the midline. This might be explained by 
the presence of skip metastasis to mediastinal lymph nodes, which is not an uncommon phenomenon in NSCLC $[23,24]$. Compared with central tumours defined by concentric lines arising from the hilum, those defined by concentric lines arising from the midline are more likely to encompass tumours in apical regions or just above the diaphragm near the midline. Tumours located in those regions might directly metastasise to upper paratracheal (station 2), supraclavicular (station 1), para-oesophageal (station 8) or pulmonary ligament (station 9) lymph nodes and not through hilar lymph nodes. Indeed, previous cadaveric studies found that $23.6 \%$ of segmental lymph channels drain directly into mediastinal lymph nodes, which were more frequent from upper lobes [25], and that lymphatic vessels from the diaphragmatic pleura drained to mediastinal lymph nodes via pulmonary ligaments [26].

Our study also compared dividing lines for the central location: concentric lines arising from the hilum in both axial and coronal images versus concentric lines arising from the midline in axial images versus sagittal lines in coronal images. We found that central location defined as the inner one-third of the hemithorax by sagittal lines was associated with occult N2 disease in a crude model, but significance disappeared in the adjusted model. None of the previous studies stated that they assessed tumour centrality in the sagittal plane (i.e. measurements were mostly made in axial images $[5,7,13]$ or not otherwise described). Likewise, the vast majority of physicians who participated in an online survey also chose concentric lines over sagittal lines [14]. Contact with the hilar structure was not recommended by any of the official guidelines and was only described in the online survey, yet was chosen by $29 \%$ of physicians [14]. In our study, central location defined as contact with the hilar structure was shown to be weakly associated with occult N2 disease only in unadjusted analysis.

Although recommended indications of pre-operative invasive mediastinal staging in patients with radiological N0 are not consistent among the major clinical guidelines, guidelines from the NCCN and ESTS include tumour size criterion, as well as central tumour [1,3]. Our study also showed the strong association of tumour size and risk of occult $\mathrm{N} 2$ disease, as in the previous studies $[5,8,9,11,13,22]$. The increasing odds of occult N2 disease per each centimetre again stresses the importance of tumour size and warrants further studies on the optimal cut-off value of tumour size in indications of invasive mediastinal staging.

There are several limitations to this study. First, it was conducted in a single referral hospital with a comprehensive cancer centre. Second, since the study population was retrospectively recruited from two separate registries, it did not include those who underwent neither surgical resection nor EBUS-TBNA (e.g. those who received stereotactic body radiotherapy or best supportive care for radiological N0 NSCLC). In these patients, occult mediastinal metastasis was usually diagnosed afterwards by image follow-up. Thus, the results of our study cannot be generalised to the whole population of patients with NSCLC and radiological N0 disease. However, using EBUS-TBNA Registry data, we included patients with radiological N0 who were confirmed to have N2 disease by EBUS-TBNA to minimise the selection bias. Third, our study determined tumour location based on the inner-most part of the tumour. Among the choices of the inner-most part, outer-most part or location of the majority of the tumour volume, about half of physicians in the online survey chose the inner-most part of the tumour [14], unlike many of the previous studies in which tumour locations were determined based on the "centre of the tumour" [5, 7, 9, $10,13]$. The exact centre of a lesion is difficult to define and it is more biologically plausible to use the inner-most part of the tumour given the direction of lymph node metastasis. Nevertheless, no pervious study has addressed this question. Fourth, although the definition of a central tumour we suggest was associated with occult $\mathrm{N} 2$ disease with statistical significance, the evidence is not sufficient to use this definition as an indication for invasive mediastinal staging. Considering that the scope of surgery is curative and thus it is important not to miss N2 disease, further studies on the clinical significance of false-negative results, risk of the procedure, cost-effectiveness and ultimately the effect on patients' survival are needed to determine the clinical efficacy of this definition of a central tumour $[27,28]$.

Motivated by the apparent lack of uniformity in the definition of central tumour location [14], our study compared seven different definitions to find the definition most predictive of occult mediastinal metastasis. Using data from a large number of NSCLC patients without mediastinal metastasis on both CT and PET-CT, we found that central tumours defined as located in the inner one-third of the hemithorax adopted by drawing concentric lines from the midline are associated with occult mediastinal metastasis in this patient group. Our study adds to the existing body of evidence by clarifying the definition of central tumour location that is the most predictive of occult mediastinal metastasis. We suggest that this classification may constitute an indication for invasive mediastinal staging in conjunction with other known risk factors.

Author contributions: Study conception and design: S.H. Shin, D.Y. Jeong and B-H. Jeong. Data acquisition and analysis: S.H. Shin, D.Y. Jeong J.H. Cho and Y.S. Choi. Data interpretation and manuscript writing: S.H. Shin, 
D.Y. Jeong and B-H. Jeong. Revision of manuscript and contribution of intellectual content: S.H. Shin, D.Y. Jeong, K.S. Lee, J.H. Cho, Y.S. Choi, K. Lee, S-W. Um, H. Kim and B-H. Jeong.

Conflict of interest: None declared.

\section{References}

1 National Comprehensive Cancer Network. Clinical Practice Guidelines in Oncology - Non-Small Cell Lung Cancer, version 2.2019. 2019. www.nccn.org/professionals/physician_gls/pdf/nscl.pdf Date last accessed: November 21, 2018.

2 Silvestri GA, Gonzalez AV, Jantz MA, et al. Methods for staging non-small cell lung cancer: diagnosis and management of lung cancer, 3rd ed: American College of Chest Physicians evidence-based clinical practice guidelines. Chest 2013; 143: e211S-e250S.

3 De Leyn P, Dooms C, Kuzdzal J, et al. Revised ESTS guidelines for preoperative mediastinal lymph node staging for non-small-cell lung cancer. Eur J Cardiothorac Surg 2014; 45: 787-798

4 Ketchedjian A, Daly BD, Fernando HC, et al. Location as an important predictor of lymph node involvement for pulmonary adenocarcinoma. J Thorac Cardiovasc Surg 2006; 132: 544-548.

5 Lee PC, Port JL, Korst RJ, et al. Risk factors for occult mediastinal metastases in clinical stage I non-small cell lung cancer. Ann Thorac Surg 2007; 84: 177-181.

6 Gomez-Caro A, Garcia S, Reguart N, et al. Incidence of occult mediastinal node involvement in cN0 non-small-cell lung cancer patients after negative uptake of positron emission tomography/computer tomography scan. Eur J Cardiothorac Surg 2010; 37: 1168-1174.

7 Park HK, Jeon K, Koh WJ, et al. Occult nodal metastasis in patients with non-small cell lung cancer at clinical stage IA by PET/CT. Respirology 2010; 15: 1179-1184.

8 Kanzaki R, Higashiyama M, Fujiwara A, et al. Occult mediastinal lymph node metastasis in NSCLC patients diagnosed as clinical N0-1 by preoperative integrated FDG-PET/CT and CT: risk factors, pattern, and histopathological study. Lung Cancer 2011; 71: 333-337.

9 Zhang Y, Sun Y, Xiang J, et al. A prediction model for N2 disease in T1 non-small cell lung cancer. $J$ Thorac Cardiovasc Surg 2012; 144: 1360-1364.

10 Chen K, Yang F, Jiang G, et al. Development and validation of a clinical prediction model for N2 lymph node metastasis in non-small cell lung cancer. Ann Thorac Surg 2013; 96: 1761-1768.

11 Farjah F, Lou F, Sima C, et al. A prediction model for pathologic N2 disease in lung cancer patients with a negative mediastinum by positron emission tomography. J Thorac Oncol 2013; 8: 1170-1180.

12 O'Connell OJ, Almeida FA, Simoff MJ, et al. A prediction model to help with the assessment of adenopathy in lung cancer: HAL. Am J Respir Crit Care Med 2017; 195: 1651-1660.

13 Gao SJ, Kim AW, Puchalski JT, et al. Indications for invasive mediastinal staging in patients with early non-small cell lung cancer staged with PET-CT. Lung Cancer 2017; 109: 36-41.

14 Casal RF, Vial MR, Miller R, et al. What exactly is a centrally located lung tumor? Results of an online survey. Ann Am Thorac Soc 2017; 14: 118-123.

15 Hellwig D, Graeter TP, Ukena D, et al. ${ }^{18}$ F-FDG PET for mediastinal staging of lung cancer: which SUV threshold makes sense? J Nucl Med 2007; 48: 1761-1766.

16 Rusch VW, Asamura H, Watanabe H, et al. The IASLC Lung Cancer Staging Project: a proposal for a new international lymph node map in the forthcoming seventh edition of the TNM classification for lung cancer. J Thorac Oncol 2009; 4: 568-577.

17 Um SW, Kim HK, Jung SH, et al. Endobronchial ultrasound versus mediastinoscopy for mediastinal nodal staging of non-small-cell lung cancer. J Thorac Oncol 2015; 10: 331-337.

18 Jhun BW, Park HY, Jeon K, et al. Nodal stations and diagnostic performances of endobronchial ultrasound-guided transbronchial needle aspiration in patients with non-small cell lung cancer. J Korean Med Sci 2012; 27: 46-51.

19 Lee KJ, Suh GY, Chung MP, et al. Combined endobronchial and transesophageal approach of an ultrasound bronchoscope for mediastinal staging of lung cancer. PLoS One 2014; 9: e91893.

20 Kim D, Choi YS, Kim HK, et al. Heterogeneity of clinical N1 non-small cell lung cancer. Thorac Cardiovasc Surg 2014; 62: 103-108

21 Kim HK, Choi YS, Kim K, et al. Outcomes of mediastinoscopy and surgery with or without neoadjuvant therapy in patients with non-small cell lung cancer who are N2 negative on positron emission tomography and computed tomography. J Thorac Oncol 2011; 6: 336-342.

22 Ong P, Grosu H, Eapen GA, et al. Endobronchial ultrasound-guided transbronchial needle aspiration for systematic nodal staging of lung cancer in patients with N0 disease by computed tomography and integrated positron emission tomography-computed tomography. Ann Am Thorac Soc 2015; 12: 415-419.

23 Riquet M, Assouad J, Bagan P, et al. Skip mediastinal lymph node metastasis and lung cancer: a particular N2 subgroup with a better prognosis. Ann Thorac Surg 2005; 79: 225-233.

24 Asamura H, Chansky K, Crowley J, et al. The International Association for the Study of Lung Cancer Lung Cancer Staging Project: proposals for the revision of the N descriptors in the forthcoming 8th edition of the TNM classification for lung cancer. $J$ Thorac Oncol 2015; 10: 1675-1684.

25 Riquet M, Hidden G, Debesse B. Direct lymphatic drainage of lung segments to the mediastinal nodes. An anatomic study on 260 adults. J Thorac Cardiovasc Surg 1989; 97: 623-632.

26 Okiemy G, Foucault C, Avisse C, et al. Lymphatic drainage of the diaphragmatic pleura to the peritracheobronchial lymph nodes. Surg Radiol Anat 2003; 25: 32-35.

27 Czarnecka-Kujawa K, Rochau U, Siebert U, et al. Cost-effectiveness of mediastinal lymph node staging in non-small cell lung cancer. J Thorac Cardiovasc Surg 2017; 153: 1567-1578.

28 Navani N, Nankivell M, Lawrence DR, et al. Lung cancer diagnosis and staging with endobronchial ultrasound-guided transbronchial needle aspiration compared with conventional approaches: an open-label, pragmatic, randomised controlled trial. Lancet Respir Med 2015; 3: 282-289. 